\title{
Tonic Immobility is Associated with PTSD Symptoms in Traumatized Adolescents
}

\author{
Andressa A Magalhaes ${ }^{1}{ }^{\prime}$ \\ Camila MF Gama $\left.{ }^{\prime}\right)^{\prime}$ \\ Raquel M Gonçalves (D) \\ Liana CL Portugal (iD) ${ }^{2}$ \\ Isabel A David (iD) I \\ Fernanda Serpeloni iD ${ }^{3}$ \\ Liana Wernersbach Pinto (iD ${ }^{3}$ \\ Simone G Assis iD $^{3,4}$ \\ Joviana $Q$ Avanci (iD ${ }^{3}$ \\ Eliane Volchan $\mathbb{D D}^{5}$ \\ Ivan Figueira (iD) ${ }^{6}$ \\ Liliane MP Vilete (iD ${ }^{6}$ \\ Mariana P Luz iD ${ }^{6}$ \\ William Berger (D) ${ }^{6}$ \\ Fatima S Erthal (iD ${ }^{5}$ \\ Mauro V Mendlowicz iD ${ }^{7}$ \\ Izabela Mocaiber iD ${ }^{8}$ \\ Mirtes G Pereira $\mathbb{D}^{\prime}$ \\ Leticia de Oliveira ${ }^{1}{ }^{\prime}$ \\ 'Biomedical Institute, Fluminense Federal \\ University, Niterói, RJ, 242 I0-I30, Brazil; \\ ${ }^{2}$ Department of Physiological Sciences, State \\ University of Rio de Janeiro, Rio de Janeiro, RJ, \\ 20550-I70, Brazil; ${ }^{3}$ Department of Violence and \\ Health Studies, Oswaldo Cruz Foundation, Rio de \\ Janeiro, RJ, $21040-900$, Brazil; ${ }^{4}$ The Neurology \\ Postgraduate Program, Hospital Gaffrée and \\ Guinle, Unirio, RJ, 20270-90I, Brazil; ${ }^{5}$ Institute of \\ Biophysics Carlos Chagas Filho, Federal University \\ of Rio de Janeiro, Rio de Janeiro, RJ, 2 I94 I-902,

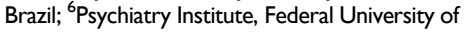 \\ Rio de Janeiro, Rio de Janeiro, RJ, 22290-I40, Brazil; \\ ${ }^{7}$ Department of Psychiatry and Mental Health, \\ Fluminense Federal University, Niterói, RJ, 24030- \\ 215, Brazil; ${ }^{8}$ Institute of Humanities and Health, \\ Federal Fluminense University, Rio das Ostras, RJ, \\ 28890-000, Brazil
}

Correspondence: Leticia de Oliveira

Biomedical Institute, Fluminense Federal

University, I0I Hernani Mello, Niterói, RJ,

24210-130, Brazil

Tel +55 21 2629-2446

Email oliveira_leticia@id.uff.br
Purpose: Growing evidence suggests that peritraumatic tonic immobility, an involuntary defensive response that involves extreme physical immobility and the perceived inability to escape, is a significant predictor of post-traumatic stress disorder (PTSD) symptomatology. However, this issue has not been specifically addressed in adolescents. Here, we investigated whether tonic immobility response experienced during the worst childhood or adolescent trauma is associated with PTSD symptom severity in a non-clinical student sample.

Methods: The sample was composed of students in 9th grade who were attending public and private schools. Symptoms of post-traumatic stress and tonic immobility were assessed using questionnaires. We performed bivariate and multivariate negative binomial regressions to examine whether tonic immobility was associated with PTSD symptomatology after controlling for confounders (peritraumatic dissociation, peritraumatic panic reactions, gender, age and time since trauma).

Results: We found an association between tonic immobility and PTSD symptom severity, even after controlling for confounders. Therefore, tonic immobility is associated with PTSD symptoms in trauma-exposed adolescents.

Conclusion: These findings highlight tonic immobility as a possible risk factor that could be used to provide direction for more targeted trauma interventions for individuals, particularly those at risk for developing PTSD. Therefore, it contributes to preventing and reducing the psychiatric burden in adolescence and later in life.

Keyswords: post-traumatic stress disorder, adolescence, youth, peritraumatic reaction, psychometry, trauma

\section{Introduction}

Adverse experiences in childhood, including childhood maltreatment and household dysfunction that occur before age 18 , were previously associated with multiple healthimpeding conditions and leading causes of death during adulthood. ${ }^{1}$ This association was expressed as a graded relationship between the number of exposure categories and the occurrence of adulthood diseases and health risk behaviours. Furthermore, the experience of adverse family environments also leads to a high risk of developing mental health problems in adolescents. ${ }^{2,3}$ In addition, a very recent paper from our group showed that childhood maltreatment is predictive of revictimization, which refers to the exposure of individuals who were victimized during childhood to subsequent traumatic events. ${ }^{4}$ According to DSM-V (Diagnostic and Statistical Manual of Mental Disorders, 5th Edition), traumatic events involve exposure to real or threatening death events, serious injury, or sexual violence. ${ }^{5}$ Post-traumatic stress disorder (PTSD) is one of the most common disorders associated with exposure to violence. 
PTSD is characterized by intrusion symptoms (eg, reexperiencing the traumatic event through unwanted upsetting memories and nightmares), avoidance (eg, avoidance of reminders of the traumatic event), negative alterations in cognition and mood (eg, inability to recall key features of the trauma, decreased interest in activities, and difficulty experiencing positive affect) and alterations in arousal and reactivity (eg, hypervigilance, sleep difficulties, and exaggerated startle response) (according to DSMV). ${ }^{5}$ There are some risk factors associated with PTSD. ${ }^{6,7}$ One risk factor is related to the emotional reactions that occur during and immediately after trauma, which are known as peritraumatic reactions. In fact, peritraumatic reactions appear to have a substantial impact on the severity, prognosis and treatment of PTSD. ${ }^{8-14,28}$ Peritraumatic dissociation and panic reactions, in particular, have been associated with PTSD symptomatology. ${ }^{15,16}$ Another peritraumatic reaction that has attracted the attention of researchers and clinicians due to its impact on PTSD severity is the tonic immobility response. ${ }^{8,10-14,28}$

Tonic immobility is an involuntary defensive response characterized by reversible profound immobility, analgesia, and relative unresponsiveness to external stimulation elicited in the context of an inescapable threat in nonhuman species. ${ }^{17}$ Reports of this phenomenon have been presented in non-human animals for three centuries. ${ }^{18}$ Tonic immobility has survival value for prey in the context of an extreme threat to life, when neither fighting nor escaping is possible; once the immobility response occurs in the prey, a predator may loosen its grip to hide the prey or to fend off other predators. ${ }^{19}$ However, only in the last few decades has the presence of tonic immobility in humans been discussed in relation to "rape-induced paralysis". ${ }^{20}$ In fact, the occurrence of tonic immobility was confirmed through a combination of psychometric instruments and retrospective reports of traumatic events in victims of sexual assault. ${ }^{21-26}$ Although tonic immobility was initially described and is more common in women who are victims of rape, tonic immobility can occur regardless of gender or type of traumatic event. ${ }^{10,12,13,28,30}$

Given that the diagnostic criteria for PTSD (according to Criterion A1 on the DSM-IV: Diagnostic and Statistical Manual of Mental Disorders, 4th Edition) include witnessing death, being exposed to the threat of death, and experiencing serious injury or sexual violation, which are also triggers for tonic immobility, one could expect an association between tonic immobility and PTSD symptoms. ${ }^{8,10-14,28,31}$ In fact, regarding the importance of the tonic immobility response in clinical samples, this peritraumatic response was the only one that remained a significant predictor of the severity of PTSD symptoms after controlling for potential confounders (negative affect, sex, and time since trauma). ${ }^{14}$ Interestingly, tonic immobility seems to be related to the severity of PTSD symptoms, not only in patients with PTSD. Indeed, Portugal et $\mathrm{al}^{13}{ }^{13}$ showed that healthy undergraduate students exposed to various types of trauma exhibited an association between the intensity of the tonic immobility response and the severity of PTSD symptoms, even controlling for potential confounders. Together, these findings highlight the importance of the tonic immobility response as a vulnerability factor toward increasing post-traumatic stress symptoms in clinical and non-clinical samples. Furthermore, experimental studies in laboratory settings have found biomarkers of tonic immobility in humans. ${ }^{27,29,32,33}$ To the best of our knowledge, Volchan et $\mathrm{al}^{32}$ conducted the first study that linked verbal reports of tonic immobility with objective measures of body immobility. This study revealed that an important proportion of PTSD patients reacted with sustained tachycardia accompanied by reduced heart rate variability and reduced body sway while listening to their personal violencerelated trauma script. These physiological alterations were accompanied by increased ratings on the tonic immobility scale. This evidence supports the idea that tonic immobility is retained in humans as a defensive strategy for responding to trauma cues.

Despite the growing evidence associating tonic immobility and PTSD symptomatology in adults, as far as we know, no study has collected tonic immobility data from periods prior to adulthood. ${ }^{10,13,14,27,32}$ In this study, we specifically collected data from adolescents. Interestingly, some findings investigating tonic immobility in nonhuman species discuss maturational influences on the development of fear responses. ${ }^{34,35}$ For humans, these maturational milestones occur during adolescence, a crucial period of brain development with relative immaturity in frontal cortical neural systems. ${ }^{36}$ It could explain adolescents' high rates of risk-taking, substance use and other dangerous behaviours. ${ }^{37,38}$ In addition, the experience of adverse family environments and living in poor households located in neighbourhoods in which antisocial behaviours occur (eg, being subjected to personal insults, violence, or theft) lead to a high risk of developing mental health problems in adolescents. ${ }^{2,3}$ In fact, adolescence is a critical stage for the onset of mental disorders. A large 
sample study with data drawn from 17 countries showed that many mental disorders, including mood, anxiety and impulse control disorders, start in childhood and adolescence. ${ }^{39}$ A meta-analysis found that almost $16 \%$ of 3563 children and adolescents (2 to 18 years) from Western and non-Western countries were exposed to a variety of traumas and met diagnostic criteria for PTSD. ${ }^{40}$ In the same vein, a US population-based study demonstrated that two in three adolescents (13 to 17 years old) suffered trauma, and nearly $5 \%$ met the PTSD criteria. ${ }^{41}$

Previous work from our group showed that a high prevalence (7.8\%) of PTSD among adolescents from public and private schools in the Brazilian city of São Gonçalo is associated with exposure to violence. Furthermore, violent communities are often reported within this population. For example, more than half of the sample have seen a dead body in their neighbourhood, and almost half have witnessed shootings or someone being beaten up, shot or killed. ${ }^{42}$ In addition, high levels of physical violence, sexual violence and psychological violence have also been reported. ${ }^{43}$ In this context, a large proportion of Brazilian adolescents growing up in urban communities with ongoing violence might also be particularly vulnerable to developing PTSD.

Taking all these risk factors into account, we conducted a cross-sectional study to investigate whether the tonic immobility response experienced during the worst trauma (as measured by the trauma index) in childhood or adolescence is associated with the severity of PTSD symptoms in adolescents. We hypothesize that increments in tonic immobility will be associated with higher levels of PTSD symptoms in trauma-exposed adolescents attending public and private schools in São Gonçalo, even after controlling for confounders. This is an important contribution to the literature because little is known about the tonic immobility experiences of this population or their correlates and because adolescents at this geographical location are particularly vulnerable to experiencing trauma due to high rates of violence. There is an urgent need to identify vulnerability factors for mental health, especially at young ages, to implement targeted trauma intervention programs for reducing the psychiatric burden affecting adolescents, particularly those living in poor regions with high levels of violence, with the associated burden on public health and social scenarios.

\section{Methods}

\section{Participants}

The present study was performed in a metropolitan region of Rio de Janeiro named São Gonçalo, a city with more than 1 million people, of which one-third are children and adolescents. It has a high proportion of low-income families (20\% of the population earned $\$ 79.4$ per month or less in 2016$)$, a lack of school attendance $(12.2 \%$ are 15-17-year-old adolescents out of school), and high rates of domestic, community and urban violence (for example, the homicide rate is 43.9 per 100,000 inhabitants). ${ }^{44,45}$

All the participants $(\mathrm{N}=1117)$ came from a crosssectional survey performed on a representative sample of 9th grade students from public and private schools in São Gonçalo, Brazil. Multistage cluster sampling with unequal selection probabilities was implemented. The distributions of the number of students by strata and schools were provided by the municipal and state education departments. A total of 43 public and 30 private schools participated in the study, usually with two 9th grade classes per school. The self-administered questionnaires were given in classrooms by experienced researchers, and the participants had an average of one hour to complete them. To support the students, if necessary, a mental health professional was available.

The exclusion criteria were participants who 1) were 18 years old or older; 2) failed to complete the questionnaires fully; 3) had experienced the worst trauma less than 1 month prior (symptoms must persist for at least a month to be classified as PTSD) (DSM-V); and 4) did not meet Criterion A1 on the DSM-IV for PTSD. ${ }^{5,31}$ The final sample was composed of 736 individuals who were predominantly female (65\%) and aged $13-17$ years $(M=14.5$; $\mathrm{SD}=0.91)($ see flow chart, Figure 1).

\section{Measures PTSD Symptoms}

The trauma index and post-traumatic stress symptoms were assessed using an adapted version of the "University of California at Los Angeles post-traumatic stress disorder reaction index" (UCLA Index), a 22-item self-reported measure of the severity of intrusive, avoidance, and hyperarousal symptoms experienced in response to a stressful life event (rated from $0=$ none of the time to $4=$ most of the time) ${ }^{46}$ This scale has been successfully used in previous studies with children and adolescents 


\section{Sample}

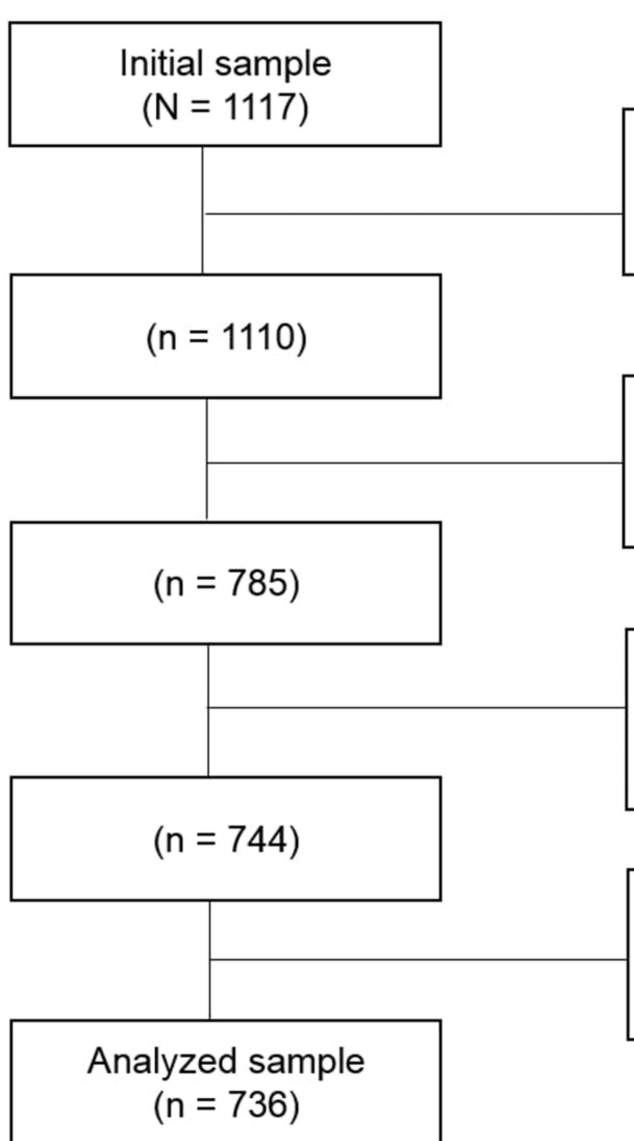

\section{Exclusion criteria}

Participants who were 18 years

old or older (7)

Participants who failed to fully complete the questionnaires (325)

\section{Participants who had experienced trauma less than 1 month before data collection (41)}

\section{Participants who did not meet Criterion A1 on the DSM-IV (8)}

Figure I Flow chart of the sample.

from São Gonçalo city and showed good internal consistency (the Cronbach's $\alpha$ was 0.88 ). ${ }^{47}$

\section{Tonic Immobility}

The Tonic Immobility Scale-Child form (TIS-C), a 10-item 7-point Likert scale, was used to assess the occurrence of peritraumatic tonic immobility. Given that some of its items assess dissociative and panic-like responses and since the goal of this study was to investigate the role of dissociative, panic, and tonic immobility reactions, we decided to exclude the items of TIS-C that overlapped with those of the Peritraumatic Dissociative Experiences Questionnaire (PDEQ) and The Physical Reactions Subscale (PRS) from our analyses. The primary advantage of this procedure was to disentangle the strict motor aspects of tonic immobility from the other peritraumatic reactions under investigation. Therefore, our evaluation of peritraumatic tonic immobility was an adaptation with four "motor" items (TIS-4) ${ }^{14,32}$ from
TIS-C, ${ }^{48}$ including (i) rate the degree to which you felt frozen or paralyzed during the event (from $0=$ not at all frozen or paralyzed to $6=$ completely frozen or paralyzed); (ii) rate the degree to which you felt unable to move even though not restrained during the event (from $0=$ could move freely to 6 = could not move at all); (iii) rate the degree to which you felt unable to call out or scream during the event (from $0=$ could scream freely to $6=$ could not scream at all); and (iv) rate the degree to which you felt unable to escape during the event even though not restrained (from $0=$ could escape easily to 6 = could not escape at all but remain "fixed"). This four-item subscale showed good internal consistency, with a Cronbach's alpha of $0.83 .{ }^{14}$

\section{Peritraumatic Dissociation}

Peritraumatic dissociation was assessed using the Peritraumatic Dissociative Experiences Questionnaire (PDEQ). ${ }^{4,50}$ For each of the 10 items, the subject rated 
the extent to which he/she had experienced each dissociative phenomenon during or immediately after trauma exposure on a 5-point Likert scale (ranging from $1=$ not at all to $5=$ extreme). The internal consistency of the PDEQ was good, with a Cronbach's alpha of $0.79 .^{51}$

\section{Panic Reactions}

The Physical Reactions Subscale (PRS) was used to measure peritraumatic panic reactions. ${ }^{52}$ Ten items were measured on a 4-point Likert scale (ranging from $1=$ not at all to $4=$ extreme) to assess the intensity of the physical symptoms of panic experienced during the traumatic event.

\section{Statistical Analysis}

Normality tests were performed to investigate the distribution of the PTSD symptoms as measured by the UCLA index (dependent variable). The Kolmogorov-Smirnov test indicated that the UCLA index scores did not follow a normal distribution.

Negative binomial models were used to address the problem of non-normality of the data. This analysis is used when data are overdispersed, and it is a very common analysis for addressing non-normal data. ${ }^{53-55}$ We performed bivariate and multivariate negative binomial regressions to examine the influence of tonic immobility responses (independent variable) on PTSD symptomatology. In addition, potential confounders were included in the model, such as dissociation and panic reactions, age, gender and time since trauma. The results are expressed as incident rate ratios (IRRs), which are an estimate of the increase of one unit in the severity of PTSD, since the other variables are held constant.

All the statistical analyses were performed using the Stata 12.0 package, and statistical significance was indicated by p-values equal to or less than 0.05 .

\section{Results}

\section{Demographics and Psychometrics Results}

The final sample was composed of predominantly female individuals (65.5\%) (see Table 1). The most common trauma reported was "hearing about the violent death or serious injury of a loved one" ( $27.2 \%)$, followed by "seeing a dead body in your town" (16.2\%) and "being in a place where an armed conflict was going on around you" (12.6\%). Table 2 shows the trauma index frequency for the entire sample. In addition, individuals usually reported more than one type of trauma. Taking all types
Table I Demographic and Psychometric Characteristics of the Sample

\begin{tabular}{|l|c|c|}
\hline \multicolumn{2}{|l|}{ Sample Characteristics } & N \\
\hline Sex & 481 & $\%$ \\
\hline Female & 253 & 65.5 \\
Male & Mean & 34.5 \\
\hline & 14.48 & Standard deviation \\
\hline Age & 34.16 & 0.91 \\
UCLA Index & 7.08 & 12.31 \\
Tonic Immobility & 17.38 & 6.47 \\
Dissociation & 15.84 & 7.96 \\
Panic Reactions & & 5.90 \\
\hline
\end{tabular}

of trauma into account (trauma index + other traumas), the mean number of traumatic events suffered for each individual was $3.8(\mathrm{SD}=2.3)$.

\section{Regression Analyses}

We performed bivariate and multivariate negative binomial regressions to examine whether tonic immobility could be associated with PTSD symptomatology after controlling for confounders. The results are expressed as incident rate ratios (IRRs), which are an estimate of a oneunit increase in PTSD severity, given that other variables are held constant. In the individual bivariate negative binomial regressions, all types of peritraumatic responses were separately associated with PTSD symptomatology (see bivariate analysis in Table 3). Note that each unit increase in tonic immobility was associated with a $2.9 \%$ increase in the IRR of PTSD symptoms. In addition, each unit increase in dissociation and panic reactions was associated with $2.7 \%$ and $3.5 \%$ increases in the IRR of PTSD symptoms, respectively. Next, we performed multivariate negative binomial regressions to examine the association of tonic immobility with PTSD symptomatology in the presence of potential confounders (dissociation and panic reactions, age, gender and time since trauma). First, we analysed the association between tonic immobility and PTSD symptoms, including dissociation and panic reactions, in the model. Each unit increase in tonic immobility was shown to be associated with a $0.9 \%$ increase in the IRR of PTSD symptoms. Second, gender, age, and time since trauma were also included in the model, and the association remained statistically significant, highlighting the relevance of tonic immobility for PTSD symptom severity (see multivariate analysis in Table 3). 
Table 2 The Trauma Index Frequency

\begin{tabular}{|c|c|c|c|}
\hline $\begin{array}{l}\text { UCLA } \\
\text { Item }\end{array}$ & Trauma Index & $\mathbf{N}$ & $\%$ \\
\hline 11 & Hearing about the violent death or serious injury of a loved one & 200 & 27.2 \\
\hline 9 & Seeing a dead body in your town (do not include funerals) & 119 & 16.2 \\
\hline 4 & Being in a place where an armed conflict was going on around you & 93 & 12.6 \\
\hline 8 & Seeing someone in your town being beaten up, shot at or killed & 78 & 10.6 \\
\hline 6 & $\begin{array}{l}\text { Seeing a family member being hit, punched or kicked very hard at home (do not include ordinary fights between } \\
\text { brothers and sisters) }\end{array}$ & 68 & 9.2 \\
\hline 7 & Being beaten up, shot at or threatened to be hurt badly in your town & 38 & 5.2 \\
\hline 5 & Being hit, punched or kicked very hard at home (do not include ordinary fights between brothers and sisters) & 38 & 5.2 \\
\hline 2 & Being in another kind of disaster, like a fire, tornado, flood or hurricane & 26 & 3.5 \\
\hline 10 & Having an adult or someone much older touch your private sexual body parts when you did not want them to & 25 & 3.4 \\
\hline 3 & Being in a bad accident, like a very serious car accident & 24 & 3.3 \\
\hline 12 & Having painful and scary medical treatment in a hospital when very sick or badly injured & 22 & 3.0 \\
\hline I & Being in a big earthquake that badly damaged the building you were in & 4 & 0.5 \\
\hline 13 & $\begin{array}{l}\text { Other than the situations described above, has anything else happened to you that was really scary, dangerous or } \\
\text { violent? }\end{array}$ & I & 0.1 \\
\hline
\end{tabular}

Table 3 Negative Binomial Regressions for the Association Between Peritraumatic Reactions and Confounding Variables with PTSD Symptoms

\begin{tabular}{|c|c|c|c|}
\hline Association with PTSD Symptoms & IRR & $95 \% \mathrm{Cl}$ & p-value \\
\hline \multicolumn{4}{|l|}{ Bivariate analysis } \\
\hline Tonic immobility & 1.029 & $1.026-1.032$ & 0.000 \\
\hline Dissociation & 1.027 & $1.025-1.029$ & 0.000 \\
\hline Panic reactions & 1.035 & $1.031-1.038$ & 0.000 \\
\hline \multicolumn{4}{|l|}{ Multivariate analysis } \\
\hline Tonic immobility (Dissociation + Panic) & 1.009 & $1.006-1.013$ & 0.000 \\
\hline $\begin{array}{l}\text { Tonic immobility (Dissociation }+ \text { Panic }+ \text { Age }+ \text { Gender }+ \text { Time } \\
\text { since trauma) }\end{array}$ & 1.009 & $1.005-1.012$ & 0.000 \\
\hline
\end{tabular}

\section{Discussion}

This is the first study to investigate the association between symptoms of PTSD and peritraumatic tonic immobility, with data collected directly from a sample of adolescents. The results showed a significant association between tonic immobility and PTSD symptom severity. Moreover, this association remained significant after controlling for confounders, particularly peritraumatic dissociation and panic reactions. Thus, this study showed that the tonic immobility response to traumatic events may have prognostic value for PTSD symptom severity in adolescents as previously described for adults, suggesting that tonic immobility would be considered a vulnerability factor in this age group.

These results are in accordance with previous studies performed by our group. In a sample of PTSD patients who had experienced urban violence, when peritraumatic tonic immobility, dissociation and panic reactions were included in the same regression model, tonic immobility was the only peritraumatic response that significantly 
predicted PTSD symptom severity. ${ }^{14}$ Interestingly, tonic immobility seems to be related to increased PTSD symptom severity not only in patients but also in healthy individuals, for example, undergraduate students who were exposed to various types of trauma but did not develop PTSD. This association remained significant after controlling for potential confounders, such as peritraumatic dissociation, peritraumatic panic reactions, negative affect, gender, type of trauma, and time since trauma. ${ }^{13}$ Taken together, these findings highlight the importance of the tonic immobility response as a risk factor for PTSD symptom severity in clinical and non-clinical samples.

In addition to the studies performed by our group, the peritraumatic tonic immobility reaction has also been indicated in the literature to be a factor that affects an individual's vulnerability to the development of PTSD. ${ }^{21,24,25}$ Hagenaars investigated the association of tonic immobility with PTSD in a large representative sample (over ages ranging from 16 to 93$){ }^{8}$ They measured peritraumatic tonic immobility, peritraumatic fear, peritraumatic dissociation, trait anxiety, dissociative tendencies, behavioural inhibition, and PTSD symptoms. Tonic immobility and trait anxiety were the most relevant predictors. More recently, Hagenaars and Hagenaars performed a two-year assessment study to test whether tonic immobility could predict poor recovery from PTSD. ${ }^{56}$ They investigated a mixed trauma sample $(\mathrm{N}=262$, age ranging from 18 to 86 years) and observed that after controlling for peritraumatic fear and dissociation, peritraumatic tonic immobility predicted PTSD symptoms in the assessment during the second year. This evidence suggests that tonic immobility impairs recovery from PTSD. Additionally, Möller et $\mathrm{al},{ }^{57}$ showed that the occurrence of tonic immobility seems to increase the risk of PTSD prevalence after sexual assault. Interestingly, the prevalence of PTSD in women who experienced extreme tonic immobility during assault was almost twice as high as that in women who did not experience tonic immobility, corroborating the idea that this response contributes to psychopathological outcomes, particularly PTSD symptoms; please see the work of Abrams et al, ${ }^{9}$ for an exception.

One possible explanation of why tonic immobility leads to PTSD symptoms is that experiencing tonic immobility can lead to self-blame (guilt), and guilt mediates the association between tonic immobility and PTSD symptoms. ${ }^{58}$ In fact, it was demonstrated that persons who experience tonic immobility during a sexual assault may tend to blame themselves for not acting appropriately to prevent or halt the attack. ${ }^{22}$ Self-blame, in turn, is linked to poorer recovery from sexual assault and may contribute to feelings of shame or guilt. ${ }^{22,59,60}$ In fact, findings from the literature suggest that guilt is associated with PTSD. ${ }^{61,62}$ For example, Guineau et al, ${ }^{63}$ demonstrated that among all analysed PTSD symptoms, blaming oneself or others for the traumatic event showed the strongest link to event centrality, the extent to which individuals integrate a traumatic event into their life story and identity. In addition, Bovin et $a l^{58}$ showed that guilt may be an important mechanism by which trauma survivors who experience tonic immobility later develop PTSD symptoms. These authors highlight the importance of educating individuals who have experienced tonic immobility to reduce guilt about peritraumatic behavioural passivity, which may in turn reduce PTSD symptoms. In addition, being blamed by others for not having reacted to the trauma, that is, a lack of social support, can be an important aggravating factor in this relationship. ${ }^{64}$

Some investigations have described adult participants reporting tonic immobility during childhood trauma. ${ }^{24-26}$ Although this evidence provides important information about tonic immobility at an early age, no study has conducted an investigation by collecting data from a sample of participants younger than adulthood. This aspect would be especially important, because it reduces the sample's retrospective bias. In the present study, data collection was performed in adolescents, and the time when they completed the psychometric scales was relatively closer to the traumatic event (childhood or adolescence), minimizing recall bias. For instance, age-related changes in memory are well documented, with evidence showing that older adults perform worse than young adults. ${ }^{65-67}$

Interestingly, studies with non-human animals discuss maturational influences on the development of fear responses, pointing to longer tonic immobility reactions with age. ${ }^{34,35}$ In humans, it would be possible that this peritraumatic response was less important at earlier ages, such as childhood or adolescence. Our results, however, showed that the tonic immobility response to traumatic events may have prognostic value for PTSD symptom severity in adolescents, as previously described for adults. Therefore, tonic immobility could be considered a vulnerability factor in this age group. When taking these factors into account, it is essential to explore the impact of experiencing tonic immobility, an involuntary 
defensive response, on PTSD symptomatology in adolescents. Mental health problems that present in adolescence can profoundly impair quality of life and might cause numerous negative developmental outcomes and psychiatric conditions in adulthood. ${ }^{36,39,68-70}$ Especially in lowand middle-income countries, where the violence and trauma loads are often high, it is crucial to elucidate the contributions of risk factors for PTSD symptom severity. Thus, knowing which individuals are at the highest risk for PTSD might provide important guidance with regard to appropriate early interventions and the allocation of mental health resources. ${ }^{71,72}$ Implementing early and specific psychological/psychiatric interventions can minimize the chances of developing mental disorders in adolescence or later in life, particularly those living in poor regions with high levels of violence, with a poor quality of healthcare and social services. Future research should focus on possible mechanisms behind the relationship between tonic immobility and PTSD symptoms, such as guilt and lack of social support, to open new avenues for the prevention and treatment of PTSD in adolescents. In addition, further studies should focus on a model that outlines multilevel determinants of health situated at the global, macro, mezzo, micro and individual levels, such as an ecological framework, to understand the risk factors affecting adolescent PTSD. ${ }^{73}$

\section{Advantages and Limitations}

This is the first study involving a representative sample of adolescents to explore the association between tonic immobility and PTSD symptoms. In addition, the use of this non-clinical sample population leads to a reduction in the biases observed in clinical populations, such as more severe cases, a higher prevalence of comorbidities, the use of medication and higher levels of functional impairment. Although there are some advantages to studying a non-clinical sample, we must point out some limitations: (1) First, these findings cannot be generalized to clinical populations. In this study, we used questionnairebased data to assess clinical phenomena and did not conduct a clinical interview, which represents a limitation for discussing the diagnosis of PTSD. However, this approach is adequate for investigating PTSD symptoms and is widely used in the literature. (2) The limitations also included the retrospective design, which may have led to recall bias. However, because we studied a sample of adolescents, the time when they completed the psychometric scales was relatively closer to the traumatic event than it would have been in an older population, minimizing recall bias. ${ }^{67}$ (3) The study was also limited by participants lost due to not completing the questionnaire, which could have impacted the representativeness of our sample. (4) Lastly, causality cannot be inferred from cross-sectional data.

\section{Conclusion}

In summary, this is the first study showing an association between peritraumatic tonic immobility and PTSD symptomatology in a sample of adolescents as described previously for adults. This association remained significant even after controlling for confounders, such as peritraumatic dissociation and panic reactions. Adolescence is a crucial brain development stage. ${ }^{36,39,68}$ These results highlight the urgency of including the evaluation of peritraumatic responses, particularly the tonic immobility response in adolescents. The presence of tonic immobility may suggest the possibility of developing more targeted interventions following trauma exposure, by focusing on individuals with higher risks of developing PTSD.

\section{Ethics Approval and Consent to Participate}

This study was approved by the Research Ethics Committee of the National School of Public Health, Fiocruz (CAAEE: 0057.0.031.000-09) and was conducted in accordance with the Declaration of Helsinki. The schools and the guardians of the adolescent participants provided written informed consent before the survey was administered.

\section{Acknowledgments}

We thank Dr Evandro Coutinho for his valuable help with the statistical analysis and description. We thank Postdoc Faperj Nota-10 (FS). Mirtes G. Pereira and Letícia de Oliveira are co-senior authors for this study.

\section{Funding}

This work was supported by CAPES (Coordenação de Aperfeiçoamento de Pessoal de Nível Superior, Finance Code 001; CAPES/PRINT); CNPq (Conselho Nacional de Desenvolvimento Científico e Tecnológico); and FAPERJ (Fundação Carlos Chagas Filho de Amparo à Pesquisa do Estado do Rio de Janeiro). 


\section{Disclosure}

The authors report no conflicts of interest in this work.

\section{References}

1. Felitti VJ, Anda RF, Nordenberg D, et al. Relationship of childhood abuse and household dysfunction to many of the leading causes of death in adults. The Adverse Childhood Experiences (ACE) Study. Am J Prev Med. 1998;14(4):245-258. doi:10.1016/s0749-3797(98)00017-8

2. Boyle MH, Georgiades K, Duncan L, Wang L, Comeau J; 2014 Ontario Child Health Study Team. Poverty, neighbourhood antisocial behaviour, and children's mental health problems: findings from the 2014 Ontario Child Health Study. Can J Psychiatry. 2019;64 (4):285-293. doi:10.1177/0706743719830027

3. Conway CC, Raposa EB, Hammen C, Brennan PA. Transdiagnostic pathways from early social stress to psychopathology: a 20-Year Prospective Study. J Child Psychol Psychiatry. 2018;59(8):855-862. doi:10.1111/jcpp. 12862

4. Gama CMF, Portugal LCL, Gonçalves RM, et al. The invisible scars of emotional abuse: a common and highly harmful form of childhood maltreatment. BMC Psychiatry. 2021;21(1):156. doi:10.1186/s12888021-03134-0

5. American Psychiatric Association (APA). Diagnostic and Statistical Manual of Mental Disorders. 5th ed. 2013.

6. Brewin CR, Andrews B, Valentine JD. Meta-analysis of risk factors for posttraumatic stress disorder in trauma-exposed adults. J Consult Clin Psychol. 2000;68(5):748-766. doi:10.1037//0022-006x.68.5.748

7. Tortella-Feliu M, Fullana MA, Pérez-Vigil A, et al. Risk factors for posttraumatic stress disorder: an umbrella review of systematic reviews and meta-analyses. Neurosci Biobehav Rev 2019;107:154-165. doi:10.1016/j.neubiorev.2019.09.013

8. Hagenaars MA. Tonic immobility and PTSD in a large community sample. $J$ Exp Psychopathol. 2016;7(2):246-260. doi:10.5127/ jep. 051915

9. Kalaf J, Vilete LMP, Volchan E, et al. Peritraumatic tonic immobility in a large representative sample of the general population: association with posttraumatic stress disorder and female gender. Compr Psychiatry. 2015;60:68-72. doi:10.1016/j.comppsych.2015.04.001

10. Abrams MP, Carleton RN, Asmundson GJG. Tonic immobility does not uniquely predict posttraumatic stress symptom severity. Psychol Trauma Theor Res Pract Policy. 2012;4(3):278-284. doi:10.1037/ a0023272

11. Fiszman A, Mendlowicz MV, Marques-Portella C, et al. Peritraumatic tonic immobility predicts a poor response to pharmacological treatment in victims of urban violence with PTSD. $J$ Affect Disord. 2008;107(1-3):193-197. doi:10.1016/j.jad.2007.07.015

12. Lima AA, Fiszman A, Marques-Portella C, et al. The impact of tonic immobility reaction on the prognosis of posttraumatic stress disorder $J$ Psychiatr Res. 2010;44(4):224-228. doi:10.1016/j.jpsychires.2 009.08.005

13. Maia DB, Nóbrega A, Marques-Portella C, et al. Peritraumatic tonic immobility is associated with PTSD symptom severity in Brazilian police officers: a Prospective Study. Rev Bras Psiquiatr. 2014;37 (1):49-54. doi:10.1590/1516-4446-2013-1267

14. Portugal LCL, Pereira MG, Tavares G, et al. Peritraumatic tonic immobility is associated with posttraumatic stress symptoms in undergraduate Brazilian students. Braz J Psychiatr. 2012;34:60-65.

15. Rocha-Rego V, Fiszman A, Portugal LC, et al. Is tonic immobility the core sign among conventional peritraumatic signs and symptoms listed for PTSD? J Affect Disord. 2009;115(1-2):269-273. doi:10.1016/j.jad.2008.09.005

16. Bryant RA, Brooks R, Silove D, Creamer M, O’Donnell M, McFarlane AC. Peritraumatic dissociation mediates the relationship between acute panic and chronic posttraumatic stress disorder. Behav Res Ther. 2011;49(5):346-351. doi:10.1016/j.brat.2011.03.003
17. Ozer EJ, Best SR, Lipsey TL, Weiss DS. Predictors of posttraumatic stress disorder and symptoms in adults: a meta-analysis. Psychol Bull. 2003;129(1):52-73. doi:10.1037/0033-2909.129.1.52

18. Ratner SC. Handbook of Clinical and Experimental Hypnosis. Macmillan; 1967.

19. Maser JD, Gallup GG. Tonic immobility and related phenomena: a partially annotated, tricentennial bibliography, 1636-1976. Psychol Rec. 1977;27(1):177-217. doi:10.1007/BF03394440

20. Gallup GG, Ledbetter DH, Maser JD. Strain differences among chickens in tonic immobility: evidence for an emotionality component. J Comp Physiol Psychol. 1976;90(11):1075-1081. doi: $10.1037 / \mathrm{h} 0078662$

21. Suarez SD, Gallup GG. Tonic immobility as a response to rape in humans a theoretical note. Psychol Rec. 1979;29(3):315-320. doi:10.1007/BF03394619

22. Bovin MJ, Jager-Hyman S, Gold SD, Marx BP, Sloan DM. Tonic immobility mediates the influence of peritraumatic fear and perceived inescapability on posttraumatic stress symptom severity among sexual assault survivors. $J$ Trauma Stress. 2008;21(4):402-409. doi:10.1002/jts.20354

23. Fusé T, Forsyth JP, Marx B, Gallup GG, Weaver S. Factor structure of the tonic immobility scale in female sexual assault survivors: an exploratory and confirmatory factor analysis. $J$ Anxiety Disord. 2007;21(3):265-283. doi:10.1016/j.janxdis.2006.05.004

24. Galliano G, Noble LM, Travis LA, Puechl C. Victim reactions during rape/sexual assault: a Preliminary Study of the immobility response and its correlates. $J$ Interpers Violence. 1993;8(1):109-114. doi: $10.1177 / 088626093008001008$

25. Heidt JM, Marx BP, Forsyth JP. Tonic immobility and childhood sexual abuse: a preliminary report evaluating the sequela of rape-induced paralysis. Behav Res Ther. 2005;43(9):1157-1171. doi:10.1016/j.brat.2004.08.005

26. Humphreys KL, Sauder CL, Martin EK, Marx BP. Tonic immobility in childhood sexual abuse survivors and its relationship to posttraumatic stress symptomatology. $J$ Interpers Violence. 2010;25 (2):358-373. doi:10.1177/0886260509334412

27. Kalaf J, Coutinho ESF, Vilete LMP, et al. Sexual trauma is more strongly associated with tonic immobility than other types of trauma a Population Based Study. J Affect Disord. 2017;215:71-76. doi:10.1016/j.jad.2017.03.009

28. Alves R de CS, Portugal LCL, Fernandes O Jr, et al. Exposure to trauma-relevant pictures is associated with tachycardia in victims who had experienced an intense peritraumatic defensive response: the tonic immobility. Front Psychol. 2014;5:1514. doi:10.3389/ fpsyg.2014.01514

29. Norte CE, Volchan E, Vila J, et al. Tonic immobility in PTSD: exacerbation of emotional cardiac defense response. Front Psychol. 2019;10:1213. doi:10.3389/fpsyg.2019.01213

30. Reichenheim M, Souza W, Coutinho ESF, et al. Structural validity of the tonic immobility scale in a population exposed to trauma: evidence from two large Brazilian samples. PLoS One. 2014;9(4): e94367. doi:10.1371/journal.pone.0094367

31. American Psychiatric Association (APA). Diagnostic and Statistical Manual of Mental Disorders. 4th ed. 1994.

32. Volchan E, Souza GG, Franklin CM, et al. Is there tonic immobility in humans? Biological evidence from victims of traumatic stress. Biol Psychol. 2011;88(1):13-19. doi:10.1016/j. biopsycho.2011.06.002

33. Volchan E, Rocha-Rego V, Bastos AF, et al. Immobility reactions under threat: a contribution to human defensive cascade and PTSD. Neurosci Biobehav Rev. 2017;76(Pt A):29-38. doi:10.1016/j. neubiorev.2017.01.025

34. Brake J, Keeley TP, Jones RB. Effect of age and presence of perches during rearing on tonic immobility fear reactions of broiler breeder pullets. Poult Sci. 1994;73(9):1470-1474. doi:10.3382/ps.0731470 
35. Campo JL, Carnicer C. Realized heritability of tonic immobility in White Leghorn hens: a replicated single generation test. Poult Sci. 1993;72(12):2193-2199. doi:10.3382/ps.0722193

36. Tamnes CK, Ostby Y, Fjell AM, Westlye LT, Due-Tønnessen P, Walhovd KB. Brain maturation in adolescence and young adulthood: regional age-related changes in cortical thickness and white matter volume and microstructure. Cereb Cortex. 2010;20(3):534-548. doi:10.1093/cercor/bhp118

37. Crone EA, Dahl RE. Understanding adolescence as a period of social-affective engagement and goal flexibility. Nat Rev Neurosci. 2012;13(9):636-650. doi:10.1038/nrn3313

38. Forbes EE, Dahl RE. Pubertal development and behavior: hormonal activation of social and motivational tendencies. Brain Cogn. 2010;72(1):66-72. doi:10.1016/j.bandc.2009.10.007

39. Kessler RC, Angermeyer M, Anthony JC, et al. Lifetime prevalence and age-of-onset distributions of mental disorders in the World Health Organization's world mental health survey initiative. World Psychiatry. 2007;6(3):168-176.

40. Alisic E, Zalta AK, van Wesel F. Rates of post-traumatic stress disorder in trauma-exposed children and adolescents: meta-analysis. Br J Psychiatry. 2014;204(5):335-340. doi:10.1192/bjp. bp.113.131227

41. McLaughlin KA, Koenen KC, Hill ED, et al. Trauma exposure and posttraumatic stress disorder in a national sample of adolescents. J Am Acad Child Adolesc Psychiatry. 2013;52(8):815-830.e14. doi:10.1016/j.jaac.2013.05.011

42. Avanci JQ, Serpeloni F, de Oliveira TP, de Assis SG. Posttraumatic stress disorder among adolescents in Brazil: a Cross-Sectional Study. BMC Psychiatry. 2021;21(1):75. doi:10.1186/s12888-021-03062-z

43. Assis SG, Avanci JQ, Santos NC, Malaquias JV, Oliveira RVC. Violência e representação social na adolescência no Brasil. [Violence and social representation in adolescence in Brazil]. Rev Panam Salud Pública. 2004;16(1):43-51. doi:10.1590/S102049892004000700006

44. Brazilian Institute of Geography and Statistics; 2017. Available from: https://cidades.ibge.gov.br/brasil/rj/sao-goncalo/panorama. Accessed March 21, 2018.

45. Institute of Applied Economic Research. Atlas da Violência. [Atlas of Violence]. Vol IPEA/Fórum Brasileiro de Segurança Pública; 2018.

46. Steinberg AM, Brymer MJ, Decker KB, Pynoos RS. The University of California at Los Angeles post-traumatic stress disorder reaction index. Curr Psychiatry Rep. 2004;6(2):96-100. doi:10.1007/s11920004-0048-2

47. Serpeloni F, Nätt D, Assis SGD, Wieling E, Elbert T. Experiencing community and domestic violence is associated with epigenetic changes in DNA methylation of BDNF and CLPX in adolescents. Psychophysiology. 2020;57(1):e13382. doi:10.1111/psyp.13382

48. Forsyth JP, Marx B, Fusé TMK, Heidt J, Gallup GG. The Tonic Immobility Scale-Child Form. Albany, NY;2000.

49. Marmar CR, Weiss DS, Metzler TJ. The peritraumatic dissociative experiences questionnaire. In: Assessing Psychological Trauma and PTSD. The Guilford Press; 1997:412-428.

50. Fiszman A, Marques C, Berger W, et al. Adaptação transcultural para o português do instrumento peritraumatic dissociative experiences questionnaire, versão auto-aplicativa. [Cross-cultural adaptation to Portuguese of the Peritraumatic Dissociative Experiences Questionnaire, self-administered version].Rev Psiquiatr Rio Gd Sul. 2005;27(2):151-158. doi:10.1590/S0101-81082005000200005

51. Birmes P, Brunet A, Benoit M, et al. Validation of the peritraumatic dissociative experiences questionnaire self-report version in two samples of French-speaking individuals exposed to trauma. Eur Psychiatry. 2005;20(2):145-151. doi:10.1016/j.eurpsy.2004.06.033

52. Resnick H. Acute panic reactions among rape victims: implications for prevention of post-rape psychopathology. NCP Clin $Q$. 1997;7:41-45.
53. Succi G, Stefanovic M, Pedrycz W. Advanced Statistical Models for Software Data. University of Alberta; 2001.

54. Holsclaw T, Hallgren KA, Steyvers M, Smyth P, Atkins DC. Measurement error and outcome distributions: methodological issues in regression analyses of behavioral coding data. Psychol Addict Behav J Soc. 2015;29(4):1031-1040. doi:10.1037/adb0000091

55. Janes A, Scotto M, Pedrycz W, Russo B, Stefanovic M, Succi G. Identification of defect-prone classes in telecommunication software systems using design metrics. Inf Sci. 2006;176(24):3711-3734. doi:10.1016/j.ins.2005.12.002

56. Hagenaars MA, Hagenaars JAP. Tonic immobility predicts poorer recovery from posttraumatic stress disorder. $J$ Affect Disord. 2020;264:365-369. doi:10.1016/j.jad.2019.11.027

57. Möller A, Söndergaard HP, Helström L. Tonic immobility during sexual assault - a common reaction predicting post-traumatic stress disorder and severe depression. Acta Obstet Gynecol Scand. 2017;96 (8):932-938. doi:10.1111/aogs.13174

58. Bovin MJ, Dodson TS, Smith BN, Gregor K, Marx BP, Pineles SL. Does guilt mediate the association between tonic immobility and posttraumatic stress disorder symptoms in female trauma survivors? Journal of Traumatic Stress. 2014;27(6):721-724. doi:10.1002/ jts. 21963

59. Frazier PA. Victim attributions and post-rape trauma. J Pers Soc Psychol. 1990;59(2):298-304. doi:10.1037//0022-3514.59.2.298

60. Ullman SE. Attributions, world assumptions, and recovery from sexual assault. J Child Sex Abuse. 1997;6(1):1-19. doi:10.1300/ J070v06n01_01

61. Henning KR, Frueh BC. Combat guilt and its relationship to PTSD symptoms. J Clin Psychol. 1997;53(8):801-808. doi:10.1002/(sici) 1097-4679(199712)53:8<801::aid-jclp3>3.0.co;2-i

62. Machado AV, Volchan E, Figueira I, et al. Association between habitual use of coping strategies and posttraumatic stress symptoms in a non-clinical sample of college students: a Bayesian approach. PLoS One. 2020;15(2):e0228661. doi:10.1371/journal.pone.0228661

63. Guineau MG, Jones PJ, Bellet BW, McNally RJ. A network analysis of DSM-5 posttraumatic stress disorder symptoms and event centrality. J Trauma Stress. 2021;34(3):654-664. doi:10.1002/ jts. 22664

64. Zoellner LA, Foa EB, Brigidi BD. Interpersonal friction and PTSD in female victims of sexual and nonsexual assault. J Trauma Stress. 1999;12(4):689-700. doi:10.1023/A:1024777303848

65. Burke DM, Light LL. Memory and aging: the role of retrieval processes. Psychol Bull. 1982;90(3):513. doi:10.1037/00332909.90.3.513

66. Light LL. Memory and aging: four hypotheses in search of data. Annu Rev Psychol. 1991;42(1):333-376. doi:10.1146/annurev. ps.42.020191.002001

67. Rhodes S, Greene NR, Naveh-Benjamin M. Age-related differences in recall and recognition: a meta-analysis. Psychon Bull Rev. 2019;26 (5):1529-1547. doi:10.3758/s13423-019-01649-y

68. Schaefer JD, Moffitt TE, Arseneault L, et al. Adolescent victimization and early-adult psychopathology: approaching causal inference using a longitudinal twin study to rule out noncausal explanations. Clin Psychol Sci. 2018;6(3):352-371. doi:10.1177/ 2167702617741381

69. Fergusson DM, Woodward LJ. Mental health, educational, and social role outcomes of adolescents with depression. Arch Gen Psychiatry. 2002;59(3):225-231. doi:10.1001/archpsyc.59.3.225

70. Warshaw MG, Fierman E, Pratt L, et al. Quality of life and dissociation in anxiety disorder patients with histories of trauma or PTSD. Am J Psychiatry. 1993;150(10):1512-1516. doi:10.1176/ ajp.150.10.1512

71. Ribeiro WS, de Mari J, Quintana MI, et al. The impact of epidemic violence on the prevalence of psychiatric disorders in Sao Paulo and Rio de Janeiro, Brazil. PLoS One. 2013;8(5):e63545. doi:10.1371/ journal.pone. 0063545 
72. Macdonald A, Danielson CK, Resnick HS, Saunders BE, Kilpatrick DG. PTSD and comorbid disorders in a representative sample of adolescents: the risk associated with multiple exposures to potentially traumatic events. Child Abuse Negl. 2010;34 (10):773-783. doi:10.1016/j.chiabu.2010.03.006
73. Glass TA, McAtee MJ. Behavioral science at the crossroads in public health: extending horizons, envisioning the future. Soc Sci Med. 2006;62(7):1650-1671. doi:10.1016/j.socscimed.2005.08.044

\section{Publish your work in this journal}

Psychology Research and Behavior Management is an international, peer-reviewed, open access journal focusing on the science of psychology and its application in behavior management to develop improved outcomes in the clinical, educational, sports and business arenas. Specific topics covered in the journal include: Neuroscience, memory and decision making; Behavior modification and management; Clinical applications; Business and sports performance management; Social and developmental studies; Animal studies. The manuscript management system is completely online and includes a very quick and fair peer-review system, which is all easy to use. Visit http://www. dovepress.com/testimonials.php to read real quotes from published authors. 